\title{
Combinations of vitamins A, D2 and D3 have synergistic effects in gastric and colon cancer cells
}

\author{
Gail B. Mahady ${ }^{1}$, Temitope O. Lawal ${ }^{1,2}$, Shitalben Patel ${ }^{1}$, Nishikant Raut ${ }^{1,3}$, and Sheila M. \\ Wicks $^{4}$
}

${ }^{1}$ Department of Pharmacy Practice, College of Pharmacy, World Health Organization Collaborating Center for Traditional Medicine, University of Illinois at Chicago, Chicago, IL, 60612 USA; ${ }^{2}$ Department of Pharmaceutical Microbiology, University of Ibadan, Ibadan, Nigeria; ${ }^{3}$ Department of Pharmaceutical Sciences, Rashtrasant Tukadoji Maharj Nagpur University, Nagpur-440033 India; ${ }^{4}$ Department of Cellular and Molecular Medicine, Rush University, Chicago, IL, 60612, USA.

Corresponding author: Sheila M. Wicks, MD, Department of Cellular and Molecular Medicine, Rush University, Chicago IL 60612, USA.

Submission Date: August 5, 2019. Acceptance Date: December $24^{\text {th }}$, 2019. Publication Date: December $30^{\text {th }}, 2019$

Citation: Mahady GB, Lawal TO, Patel S, Raut N, Wicks SM. Combination of vitamins A, D2 and D3 have synergistic effects in gastric and colon cancer cells. Functional Foods in Health and Disease 2019; 9(12): 749-771. DOI: https:/doi.org/10.31989/ffhd.v9i12.646

\begin{abstract}
Background: Vitamin D was first hypothesized to play a role in cancer chemoprevention in 1980 when it was observed that there was a higher rate of colon cancer in the Northern USA as compared with populations living in the South. While cholecalciferol (vitamin D3) has been tested in many cancer-cell lines, published results for ergocalciferol (vitamin D2) are lacking for most epithelial cell cancers, and combination studies of both D2 and D3 and vitamin A (retinoic acid) are lacking in general. The goal of the study was to investigate the effects of vitamins D2, D3, and A, alone and in combination on the growth of all gastric and colon cancer cell lines in vitro.
\end{abstract}

Methods: Colon (SW480 and HCT-116) and gastric (AGS and NCI-N87) cell lines were treated with varying concentrations of D2, D3 and all-trans retinoic acid (ATRA) and combinations thereof. Cell viability and cytotoxicity were measured using the CellTiter-Gloß 2.0 assay, while caspase activities and cytotoxicity were determined using the Caspase-Glo® 3/7, Caspase 8, ApoTox-Glo ${ }^{\text {TM }}$ Triplex assays. Autophagy was determined using the CYTO-ID ${ }^{\circledR}$ Autophagy Detection Kit 2.0. Gene expression studies were performed using qPCR.

Results: Both vitamin D2 and D3 inhibited the growth of all cell lines tested, with $\mathrm{IC}_{50}$ ranging from 19-56 $\mu \mathrm{M}$. However, when combined (1:1), the $\mathrm{IC}_{50}$ for the combination of D2 and D3 was significantly reduced to a range of 5-6.0 $\mu \mathrm{M}$ indicating synergism. ATRA also inhibited the growth 
of all cell lines tested with an $\mathrm{IC}_{50}$ range of 2.6 to $5.6 \mu \mathrm{M}$. When ATRA was combined with D2 and $\mathrm{D} 3$, the $\mathrm{IC}_{50} \mathrm{~s}$ were significantly reduced to 0.65 to $1.4 \mu \mathrm{M}$, further indicating synergistic effects. In the gastric and colon cancer cell lines, the combination induced apoptosis via caspase $3 / 7$ and 8 , increased the Bax/Bcl-2 ratio, while in the SW480 colon cancer line, the combination also induced autophagy.

Conclusion: Our data demonstrated that vitamins D2, D3 and ATRA inhibit the proliferation of colon and gastric cancer cells. The combinations of D2+D3 or ATRA+D2+D3 had synergistic effects or additive effects on all cell lines tested, increased Bax expression and the Bax/Bcl-2 ratio, and increased caspase 3/7 and 8 activities to favor apoptosis. In SW480 colon cancer cells the combination also induced autophagy. This data suggest that combinations of vitamins A and D have synergistic effects in colon and gastric cancers, and considering the potential clinical implications, further research is justified.

Key words: apoptosis, autophagy cholcalciferol, ergocalciferol, gastric cancer, colon cancer, caspase, synergism

\section{BACKGROUND}

In 1980, Garland and Garland hypothesized that ultraviolet light (UVB) and vitamin D may reduce colon cancer risk [1]. Since then, this hypothesis has gained considerable support through wide variety of scientific studies including geographical, ecological, observational, mechanistic, and clinical trials [2-10]. It has now been shown that higher vitamin D levels reduced the risk of colorectal, prostate, and breast cancers, and vitamin D deficiencies have been associated with gastric adenocarcinomas [1-10]. Thus, for patients with gastric cancers, the serum level of vitamin $\mathrm{D}$ is now considered a significant independent prognostic factor, and lower vitamin $\mathrm{D}$ levels are associated with poorer prognosis [9]. For colorectal cancer, strong evidence suggests that elevated serum vitamin $\mathrm{D}$ levels and intake are inversely associated with colorectal adenoma incidence and recurrence [7,10-11]. Like gastric cancers, a better overall prognosis and survival were observed in colorectal cancer patients having higher plasma vitamin D levels at diagnosis [10-11].

In a diet, vitamin D exists in two forms: vitamin D3 (cholecalciferol; synthesized from 7dehydrocholesterol; animal sources), and vitamin D2 (ergocalciferol; plant sources, Figure 1). Cholecalciferol is naturally synthesized in the skin after exposure to UV-B light and is a prohormone that is converted into the active 1,25-dihydroxyvitamin $\mathrm{D}$ via the liver and kidneys (Figure 1) [8]. Ergocalciferol, is a pro-vitamin D2 compound produced by UV-B irradiation of the plant sterol ergosterol in nuts, seeds, legumes and fungi (mushrooms; Figure 1). Ergocalciferol (D2) differs from D3 by one double bond between C22 and C23 positions and one methyl group at C24 in the side chain (Figure 1) [8]. These structural differences reduce vitamin D2's affinity for the vitamin D binding protein (VDBP), increases its clearance from blood, and limits its conversion to 25-hydroxy vitamin $\mathrm{D}$, as well as alters its metabolism [8]. However, both $1,25(\mathrm{OH}) 2 \mathrm{D} 2$ and 1,25(OH)2D3 have similar affinities for the vitamin D receptor (VDR), and the DNA binding sites of vitamin D response element (VDRE) [8].

Along with vitamin $\mathrm{D}$, vitamin A exists in multiple forms including retinol, retinal, retinoic acids, and provitamin $\mathrm{A}$ carotenoids, such as $\beta$-carotene. The impact of vitamin $\mathrm{A}$ on cancer risk 
was first reported in 1926, when it was observed that that gastric cancers were increased in rats fed a vitamin A-deficient diet [12-13]. Later experimental data demonstrated that all-trans retinoic acid (ATRA) was effective against leukemia and induced the differentiation of HL-60 leukemia cells, as well as inhibited the growth of gastric and breast cancers [14-15]. ATRA is the preferred isomer as compared with the cis-retinoic acid isomer, and it has been demonstrated that ATRA has better efficiency both in vitro and in vivo [14-15]. Thus, along with vitamin D, vitamin A (retinol, retinoic acid) and the carotenoids have also been shown to have a significant impact on cancer chemoprevention and treatment, most notably in cancers derived from epithelial tissues [12-16].

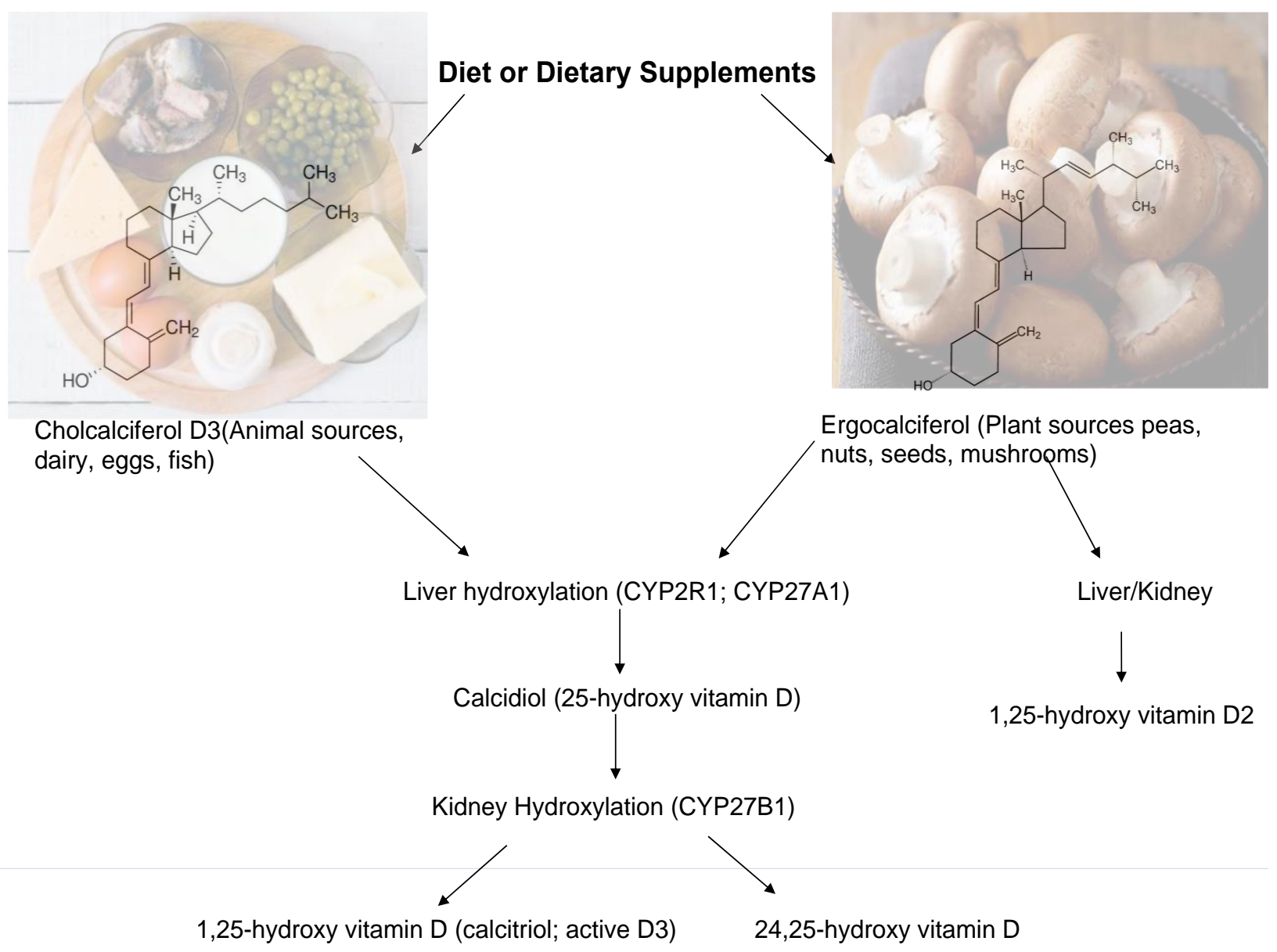

Figure 1. Metabolism of vitamins D2 and D3 to the active form of vitamin D3 (1,25hydroxycholcaliferiol; calcitriol).

More recently, it has been hypothesized that combinations of dietary compounds, including carotenoids and vitamin D, may be more effective in preventing or reducing cancer cell proliferation [16-18]. In one study, a combination of vitamin A and D was observed to synergistically enhance apoptosis in prostate cancer cells [18], suggesting that further research in this area is justified. Research and development of vitamin A, beta-carotene and other carotenoids, and vitamin D combinations in epithelial based cancer cell lines would greatly enhance our understanding of potential benefits and may define novel mechanisms of action for future animal and human studies. Since vitamins A and D have separately been shown to have anti-proliferative effects in both colon and gastric cancers, we have investigated the antiproliferative and synergistic 
effects of all-trans retinoic acid (ATRA) in combination with vitamins D2 and D3 in gastric cancer (GC) cell lines AGS and NCI-N87, as well as the colon cancer (CC) cell lines HCT-116 and SW480.

\section{METHODS}

\section{Cell culture and maintenance}

The colon cancer cell lines SW480 and HCT116 were a gift from Dr. J.J. Johnson of the Department of Pharmacy Practice, University of Illinois, Chicago. The gastric cancer cell lines AGS (ATCC ® CRL1739TM) and NCI-N87 (ATCC ® CRL5822TM) were obtained from ATCC Manassas, VA, USA. AGS cells were grown and maintained in F-12K medium (ATCC 30-2004) supplemented with 10\% fetal bovine serum (FBS) (Gibco, Life Technology, Grand Island, NY, USA) plus $1 \%$ antibiotics [10,000 IU penicillin per $\mathrm{mL}$ and $10 \mathrm{mg}$ per $\mathrm{mL}$ of streptomycin](1\% P/S) (Corning, Mediatech Inc., Manassas, VA, USA). NCI-N87 cells were grown and maintained in RPMI 1640 (Gibco 1X) A 1049-01 plus 4.5 g/L D-Glucose, 2.83 g/L HEPES Buffer + Lglutamine $+1.5 \mathrm{~g} / \mathrm{L}$ sodium bicarbonate $+110 \mathrm{mg} / \mathrm{L}$ sodium pyruvate supplemented with $10 \%$ FBS and 1\% P/S. The SW480 cells were grown and maintained in MEM 1X medium (Gibco, Life Technology, Grand Island, NY, USA) supplemented with 10\% FBS plus 1\% P/S. HCT 116 cells were grown and maintained in McCoy's 5a Medium (Gibco, Life Technology, Grand Island, NY, USA) supplemented with $10 \% \mathrm{FBS}$ and $1 \% \mathrm{P} / \mathrm{S}$ while All cells were incubated at $37^{\circ} \mathrm{C}$ in a humidified atmosphere of $5 \% \mathrm{CO}_{2}$ and $95 \%$ air. The cells were grown in monolayer and maintained in exponential growth. At $80 \%$ confluence, cells were harvested by adding $0.25 \%$ trypsin/EDTA and counted by means of Trypan blue and hemocytometer. The cells were then resuspended at appropriate concentration and plated for cellular assays.

\section{Cell Viability Assay}

Colon and gastric cancer cells were seeded in triplicate at $2.5 \times 10^{4}$ cells in $100 \mu \mathrm{l} /$ well in opaquewalled 96-well plate. Control wells containing culture medium supplemented with 10-20\% FBS and $1 \%$ Penicillin/Streptomycin) without cells to determine background luminescence. The cells were left to attach overnight in the plate. Vitamins A, D2, D3 and ATRA were purchased from Sigma-Aldrich (St. Louis, MO) and analyzed by LC/MS. The culture medium was aspirated and the fresh medium added to the wells before the addition of the vitamin A, D3, D2 $(1-100 \mu \mathrm{g} / \mathrm{ml}$ in $0.01 \%$ DMSO) and combinations thereof. Drug control (5-Fluorouracil and Doxorubicin) and vehicle control $(0.01 \%$ DMSO) wells were also prepared simultaneously and plates incubated in a humidified incubator at $37^{\circ} \mathrm{C}$ in an atmosphere of $5 \% \mathrm{CO}_{2}$ for 72 hours. At the end of the incubation period, the plate and its contents were equilibrated to room temperature for approximately 30 minutes. A $100 \mu \mathrm{l}$ of CellTiter-Glo 2.0 Reagent (Promega Corporation, Madison, WI, USA) was added to each well. The contents were mixed for 2 minutes on an orbital shaker to induce cell lysis and the plate was incubated at room temperature for 10 minutes to stabilize the luminescent signal. Luminescence signal was read using the Synergy HT Plate reader (Biotek, Winooski, VT) and Gen5 1.11 software. The $\mathrm{IC}_{50}$ defined as the concentration that causes $50 \%$ inhibition of cell growth after exposure to extract for 72 hours was calculated using $\log$ (inhibitor) vs. normalized response analysis with GraphPad Prism 8.0. (GraphPad Software, Inc. 
La Jolla, CA, USA). The ATP content of the cells was also measured using the CellTiter-Glo 2.0 assay kit. The results of this assay were measured at A 570nm using an Enzyme-Immunoassay plate reader, using five concentrations to determine $\mathrm{IC}_{50}$ (Biorad, USA).

\section{Apoptosis Assays, Caspase-Glo ${ }^{\circledR} 3 / 7$ and Caspase-Glo ${ }^{8} 8$}

Test cells were seeded in triplicate at a density of $2.5 \times 10^{4}$ cells in $100 \mu \mathrm{L} /$ well in opaque-walled 96-well plate. The cells were left to attach overnight in the plate. The vitamin D2, D3 and ATRA were added to the test wells at the $\mathrm{IC}_{50}$ concentrations. Caspase-Glo® 3/7 and CaspaseGlo®8reagents (Promega Corporation, Madison, WI, USA) were prepared according to manufacturer's instruction and allowed to equilibrate to room temperature. The test plates containing treated cells as well as controls were removed from the incubator after incubation and allowed to equilibrate to room temperature. A $100 \mu$ of Caspase-Glo® 3/7 or Caspase-Glo® 8 reagent was added to each well of a 96-well plate containing $100 \mu \mathrm{l}$ of blank, negative control cells and treated cells in culture medium. The contents of wells were gently mixed using a plate shaker at 300-500 rpm for 30 seconds and incubated at room temperature for 2 hours. The luminescence of each sample was read using the Synergy HT Plate reader (Biotek, Winooski, VT, USA) and Gen5 1.11 software.

\section{Apoptosis Assay: ApoToxGlo ${ }^{\mathrm{TM}}$ Triplex Assay}

Ninety-six (96) well assay plates containing cells in medium at a density of $2.5 \times 10^{4}$ cells in 100 $\mu \mathrm{l} /$ well in triplicate were set up. After overnight incubation to allow attachment of cells, the combination of vitamin D2, D3 and ATRA at the $\mathrm{IC}_{50}$ concentrations and vehicle controls were added to appropriate wells at a final volume of $100 \mu \mathrm{l}$ per well. Plates were incubated appropriately, before addition of $20 \mu \mathrm{l}$ of viability/cytotoxicity reagent containing both GF-AFC substrate and bis-AAF-R110 substrate to all wells, and briefly mixed by orbital shaker (300-500 rpm for $\sim 30$ seconds). Plates were incubated for 30 minutes at $37^{\circ} \mathrm{C}$ and fluorescence measured at $400 \mathrm{ex} / 505 \mathrm{em}$ (viability) and 485ex/520em (cytotoxicity). A $100 \mu \mathrm{l}$ of Caspase-Glo® 3/7 reagent was added to all wells, briefly mixed by orbital shaker (300-500 rpm for 30 seconds) and incubated for 30 minutes at room temperature. Luminescence was measured using the Synergy HT Plate reader (Biotek, Winooski, VT) and Gen5 1.11 software to detect caspase activation.

\section{Autophagy}

Autophagy was monitored and measured using a Cyto-ID Autophagy Detection Kit. Cyto-ID Autophagy Detection Kit (Enzo Biochem Inc., New York, NY) for detecting autophagy, according to manufacturer instructions. The assay provides a rapid, specific and quantitative approach for monitoring autophagic activities in vitro. The 488nm-excitable green fluorescent detection reagent supplied in kit has strong fluorescence in vesicles produced during autophagy. Exponentially growing SW480 cells were seeded into 96 well plate at a density of $2.5 \times 10^{5}$ cells. After overnight incubation at $37^{\circ} \mathrm{C}$, cells were exposed to the combination ATRA+V2+V3 at the $\mathrm{IC}_{50}$ concentration and rapamycin (RPM; inducer of autophagy), and chloroquine (CLQ; a lysosomal inhibitor) were included as positive controls. Following treatment, the cells were washed once in PBS and resuspended in $100 \mu \mathrm{l}$ of dual color detection solution (Cyto-ID Green and Hoechst 
autophagy detection reagent) and incubated at $37^{\circ} \mathrm{C}$ for 30 minutes. The cells were washed twice with assay buffer and re-suspended in $100 \mu \mathrm{l}$ assay buffer. Plate was analyzed with Synergy HT Plate reader (Biotek, Winooski, VT) and Gen5 software with (Excitation 480 nm, Emission 530) for Cyto ID green, and the Hoechst 33342 Nuclear Stain was read with a (Excitation 340, Emission 480).

\section{RNA Isolation}

Test cells were seeded at a density of $1.0-1.2 \times 10^{6}$ cells in $1 \mathrm{ml}$ per well of a 6-well plate and incubated overnight for cell attachment. Total RNA was extracted from cells after treatment for 2, 4, 8 hours at the $\mathrm{IC}_{50}$ concentration using Trizol (ThermoFisher Scientific, Waltham, MA, USA), according to the manufacturer's instructions. Untreated control cells were included as negative controls. The concentration and quality of RNA were determined by measuring absorbance at 260 $\mathrm{nm}$ and $280 \mathrm{~nm}$ on Synergy HT Take 3 (Biotek, Winooski, VT, USA) and Gen5 1.11 software.

\section{Quantitative polymerase chain reaction}

Total RNA was reverse transcribed and amplified using Power SYBR Green RNA- to-CT 1- step kit (Applied Biosystems, Foster City, CA, USA), as described by manufacturer, with the Step One Plus Real Time PCR System (Applied Biosystems, Foster City, CA, USA). Primer sequences were selected from previously published papers and are shown in Table 1. Briefly, each reaction was performed in triplicate in a $10 \mu \mathrm{l}$ volume containing Power SYBR Green RT-PCR Mix (2X), 200 $\mathrm{nM}$ of each primer, RT Enzyme Mix (125X) and 100ng RNA. The cycling conditions were as follows: $48^{\circ} \mathrm{C}$ for 30 minutes, $95^{\circ} \mathrm{C}$ for 10 minutes, followed by 50 cycles of $95^{\circ} \mathrm{C}$ for 15 seconds and $60^{\circ} \mathrm{C}$ for 1 minute. PCR reaction specificity was confirmed by melt curve analysis at $95^{\circ} \mathrm{C}$ for 15 seconds, $60^{\circ} \mathrm{C}$ for 15 seconds, $95^{\circ} \mathrm{C}$ for 15 seconds. The quantitation of gene expression was performed using $\beta$-actin gene as an endogenous control and relative to the calibrator (control cells) using the $\Delta \Delta \mathrm{CT}$ calculation.

Table 1: Sequences of human primer used in real-time PCR analysis were obtained from previously published works [19-25].

\begin{tabular}{lll}
\hline Human gene & Forward primer sequence (5' to 3') & Reverse primer sequence (5' to 3') \\
\hline Bcl-2 & CGCATCAGGAAGGCTAGAGT & AGCTTCCAGACATTCGGAGA \\
Bax & TGCCAGCAAACTGGTGCTCA & GCACTCCCGCCACAAAGATG \\
$\beta$-actin & TGACGTGGACATCCGCAAAG & CTGGAAGGTGGACAGCGAGG \\
\hline
\end{tabular}

\section{Combination assay and fractional inhibitory concentration}

The combination effect of the test compounds was investigated using in 96 well plates and evaluated using fractional inhibitory concentration (FIC) index as previously described [26-27]. The $\mathrm{IC}_{50}$ protocol remained the same as above. The concentrations tested ranged from three dilutions below the $\mathrm{IC}_{50}$ to twice the $\mathrm{IC}_{50}$. All possible combinations, including a control without any vitamins or ATRA, were tested and performed in triplicate. The combination results were quantified using the fractional inhibitory concentration (FIC) index calculated from the $\mathrm{IC}_{50}$ of A 
in combination divided by the $\mathrm{IC}_{50}$ of the concentrations of A alone. Similarly, for compound B and $\mathrm{C}$. The $\Sigma$ FIC index was calculated using the equation $\Sigma$ FIC $=$ FIC A + FIC B + FIC C and the results used to determine if synergy, addition or antagonism as a result of interactions between the pure compound. Using this method, the $\Sigma F I C$ index was interpreted as follows: $\leq 0.5$, synergy; > 0.5 to 1 , additive; $>1$ to 4 , indifference; $>4$, antagonism [26-27].

To further investigate the cytotoxicity of the test agents, a time-kill study was performed using the ApoToxGlo ${ }^{\circledR}$ Kit according to the manufacturer's instructions. ApoTox-Glo ${ }^{\mathrm{TM}}$ Triplex Assay combines measures viability, cytotoxicity and apoptosis events in the same cell-based assay well. Viability and cytotoxicity are determined by simultaneously measuring two differential protease biomarkers. The live-cell protease activity is measured using a fluorogenic, cell-permeant peptide substrate (GF-AFC Substrate) and is restricted to live cells. A cell-impermeant, fluorogenic peptide substrate (bis-AAF-R110 Substrate) can simultaneously to measure dead-cell protease activity in cells that have lost membrane integrity. The second reagent containing luminogenic DEVD-peptide substrate for caspase-3/7 and Ultra-Glo ${ }^{\text {TM }}$ Recombinant Thermostable Luciferase, in which caspase-3/7 cleavage of the substrate releases luciferin, and the light output was measured, allowing for the correlation of caspase-3/7 activation as a key indicator of apoptosis. Luminescence was measured using the Synergy HT Plate reader and Gen5 1.11 software to detect caspase activation.

HCT116 and SW480 were cultured in media supplemented with $10 \%$ fetal bovine serum (FBS) and incubated at $37^{\circ} \mathrm{C}$ with 24 hours. A final inoculum was measured at time 0 and subsequent viable counts were carried out at 8,12, 24, 48 and 72 hours. The killing rates were determined by plotting $\log 10$ cell counts against time. A cytotoxic effect was determined by a $\geq 3$ $\log 10$ (99.9\% killing) decrease in cell count at the specified time.

\section{Statistical Analysis}

Statistical analysis was performed using GraphPad/Prism version 8.0 (GraphPad Software, Inc. La Jolla, CA, USA). Data was presented as mean \pm SD. For the qPCR analysis, one-way ANOVA followed by Tukey's and Dunnett's Multiple Comparison Tests were used. Statistical findings of $\mathrm{p}<0.05$ were considered statistically significant.

\section{RESULTS}

Vitamins D2, D3 and ATRA and combinations inhibit colon and gastric cancer cell proliferation and are synergistic in combination

Vitamins D2, D3 and ATRA and combinations thereof inhibited the growth of all colon and gastric cancer cell lines tested (Table 2). However, neither $\beta$-carotene or retinol alone were active in concentrations up to $50 \mu \mathrm{g} / \mathrm{ml}$. Both vitamins D2 and D3 inhibited the growth of all colon (CC) and gastric cancer (GC) cell lines in a concentration-dependent manner, with inhibitory concentrations ( $\mathrm{IC}_{50}$ ) ranging from 19.43 to $57.71 \mu \mathrm{M}$ (Table 2; Figures 2-5). However, when vitamin D2 and D3 were combined together, at a ratio of $1: 1$, the $\mathrm{IC}_{50}$ for the combination was reduced by 4 to 10 -fold to a range of 5.0 to $6.5 \mu \mathrm{M}$ depending on the cell line, indicating synergistic activities, with the exception of SW480 CC cells where the combination of D2+D3 was additive (Tables 3 and 4; Figure 6). All-trans retinoic acid (ATRA) also inhibited the proliferation of all 
cell lines tested, with an $\mathrm{IC}_{50}$ range of 1.8 to $5.6 \mu \mathrm{M}$ (Table 2, Figure 6). When ATRA was combined with D2 and D3, the $\mathrm{IC}_{50}$ concentrations were significantly $(\mathrm{p}<0.0001)$ reduced by 3 to 4-fold to 0.65 to $1.38 \mu \mathrm{M}$, also indicating synergism (Tables 3 and 4, Figure 6). The FICs were calculated from the $\mathrm{IC}_{50}$ of the compounds in combination, divided by the $\mathrm{IC}_{50}$ of the concentrations of the compound alone (Table 3). Change in the FIC ( $\sum$ FIC) for the combination of ATRA+D2+D3 and the combination of D2 + D3 were determined using the FIC results and are presented in Table 4. The $\Sigma$ FIC index was calculated using the equation $\Sigma$ FIC $=$ FIC A + FIC B + FIC $\mathrm{C}$ and the results used to determine synergism, addition or antagonism as a result of interactions between the pure compounds. Using this method, the $\Sigma$ FIC index was interpreted as follows: $\leq 0.5$, synergy (S); $>0.5$ to 1 , additive (A); $>1$ to 4 , indifference (I); $>4$, antagonism (AN). The combinations of D2+D3 were synergistic in HCT-116, AGS and NCI-N87 cell lines, but in SW480 CC cells, the combination of D2+D3 was additive (Table 4). The combination of ATRA+D2+D3 was synergistic in both the GC and CC cell lines (Table 4). 5-Fluoruracil (5-FU), a pyrimidine analogue used as an anticancer agent used to treat solid tumors such as colon, rectal, breast, gastric, pancreatic, ovarian, bladder and liver cancers was used as a positive control drug, and was active against all four cell lines (Table 2). While doxorubicin, an anthracycline derivative that blocks topo isomerase 2, was active against the gastric cancer cell lines, with $\mathrm{IC}_{50}$ concentrations comparable with those reported in the published literature (Table 2) [28-31]. These results demonstrate that the combinations of D2+D3 and ATRA+D2+D3 were synergistic in reducing colon and gastric cancer cell proliferation. Interestingly, in the case of the SW480 colon and AGS gastric cancer cell lines, the in vitro data suggest that the combination of ATRA+D2+D3 maybe more effective than 5-FU (Table 2).

Table 2. IC $\mathrm{I}_{50}$ concentrations of tested compounds against colon and gastric cancer cell lines. The $\mathrm{IC}_{50}$ defined as the concentration that causes $50 \%$ inhibition of cell growth after exposure to extract for 72 hours was calculated using GraphPad Prism 8.0. (GraphPad Software, Inc. La Jolla, CA, USA). NA = not active in concentrations tested.

\begin{tabular}{|c|c|c|c|c|c|c|c|c|c|}
\hline $\begin{array}{l}\text { Cell } \\
\text { lines }\end{array}$ & $\begin{array}{l}\text { Beta } \\
\text { carotene Up } \\
\text { to } 50 \propto \mathrm{cg} / \mathrm{ml}\end{array}$ & $\begin{array}{l}\text { Vitamin A } \\
\text { (retinol) Up to } \\
50 \propto \alpha g / m l\end{array}$ & $\begin{array}{l}\text { All- } \\
\text { transretinoic } \\
\text { acid }(A T R A) \\
I C_{50} \propto \mathcal{M} \\
\end{array}$ & $\begin{array}{l}\text { Vit D2 } \\
I C_{50} \\
\propto C M\end{array}$ & $\begin{array}{l}\text { Vit D3 } \\
I C_{50} \\
\propto \propto \propto M\end{array}$ & $\begin{array}{l}\text { Vit D2 + } \\
\text { D3 IC } C_{50} \\
{ }_{\propto c M}\end{array}$ & $\begin{array}{l}\text { Vit D2 + } \\
\text { D3 + } \\
\text { ATRA IC } C_{50} \\
\propto c M\end{array}$ & $\begin{array}{l}\text { 5-Fluoro- } \\
\text { uracil (5- } \\
F U) I C_{50} \\
\alpha g / m l\end{array}$ & $\begin{array}{l}\text { Doxorubicin } \\
\text { (Doxo) IC } C_{50} \\
\propto \alpha g / m l\end{array}$ \\
\hline SW480 & NA & NA & 3.83 & 19.43 & 30.91 & 6.51 & 1.38 & 3.42 & ND \\
\hline НCT-116 & NA & NA & 5.66 & 34.12 & 29.97 & 6.22 & 1.1 & 0.98 & ND \\
\hline AGS & NA & NA & 2.93 & 22.32 & 57.71 & 6.32 & 0.81 & 18.64 & 0.079 \\
\hline NCI-N87 & NA & NA & 2.66 & 31.63 & 40.02 & 6.33 & 0.65 & 0.097 & 0.048 \\
\hline
\end{tabular}

Table 3. Fractional inhibitory concentration (FIC) index for ATRA, D2 and D3. FICs were calculated from the $\mathrm{IC}_{50}$ of the compound in combination divided by the $\mathrm{IC}_{50}$ of the concentrations of the compound alone. $\mathrm{A}=$ in combination with ATRA+D2+D3; b= in combination with $\mathrm{D} 2+\mathrm{D} 3$.

\begin{tabular}{lllll}
\hline FIC & HCT116 & SW480 & AGS & NCI-N87 \\
\hline ATRA & 0.19 & 0.36 & 0.27 & 0.22 \\
D2 $^{\mathrm{a}}$ & 0.03 & 0.07 & 0.03 & 0.02 \\
D3 $^{\mathrm{a}}$ & 0.04 & 0.04 & 0.01 & 0.02 \\
D2 $^{\mathrm{b}}$ & 0.18 & 0.33 & 0.28 & 0.2 \\
D3 $^{\mathrm{b}}$ & 0.21 & 0.21 & 0.11 & 0.16 \\
\hline
\end{tabular}


Table 4. Change in the FIC $\left(\sum F I C\right)$ for the combinations of ATRA+D2+D3 and the combination of D2 + D3. The $\Sigma$ FIC index was calculated using the equation $\Sigma$ FIC $=$ FIC A + FIC B + FIC C and the results used to determine if synergy, addition or antagonism as a result of interactions between the pure compounds. Using this method, the $\Sigma$ FIC index was interpreted as follows: $\leq 0.5$, synergy (S); $>0.5$ to 1 , additive (A); $>1$ to 4 , indifference (I); > 4, antagonism (AN).

\begin{tabular}{l|c|c|c|c|}
\hline$\Sigma$ FIC & HCT116 (A or S) & SW480 (A or S) & AGS (A or S) & NCI-N87 (A or S) \\
\hline ATRA+D2+D3 & $0.26($ S $)$ & $0.47($ S $)$ & $0.31($ S) & $0.26($ S) \\
D2+D3 & $0.39(\mathrm{~S})$ & $0.54(A)$ & $0.39(\mathrm{~S})$ & $0.36(\mathrm{~S})$ \\
\hline
\end{tabular}

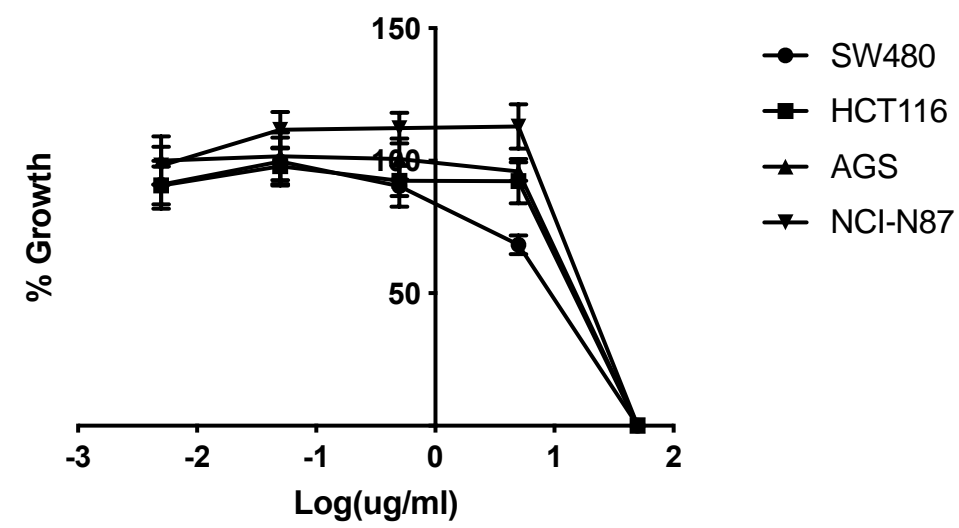

Figure 2. Concentration-dependent effects of vitamin D2 on colon and gastric cancer proliferation. This shows a concentration dependent reduction in HCT116 and SW480 colon cancer proliferation after treatment with vitamin D2 or D3.

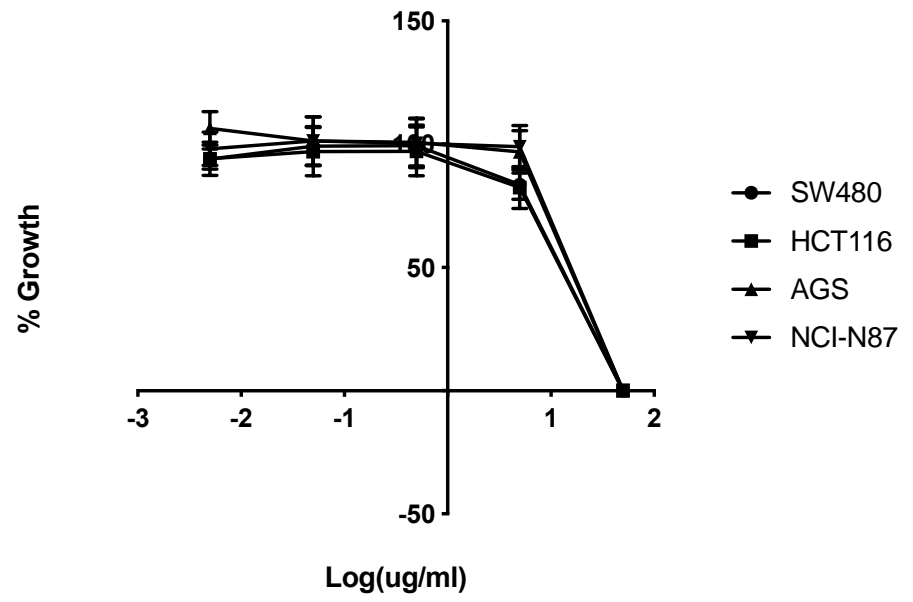

Figure 3. Concentration-dependent effects of vitamin D3 on colon and gastric cancer cell proliferation. This shows a concentration-dependent reduction in cell proliferation in gastric cancer cell lines AGS and NCI-N87 after treatment with increasing concentrations of D2 or D3.

Figures 2-3. HCT116 and SW480 colon cancer and AGS and NCI-N87 gastric cells were treated with increasing concentrations of D2 or D3 at $1-100 \mu \mathrm{g} / \mathrm{mL}$ in 96 well plates and incubated at $37^{\circ} \mathrm{C}$ in $5 \% \mathrm{CO}_{2}$ for 72 hours. Cell proliferation/cytotoxicity was determined using a CellTiter- 
Glo® 2.0 Reagent. Luminescence signal was determined using a Synergy HT Plate reader (Biotek, Winooski, VT) and Gen5 1.11 software.

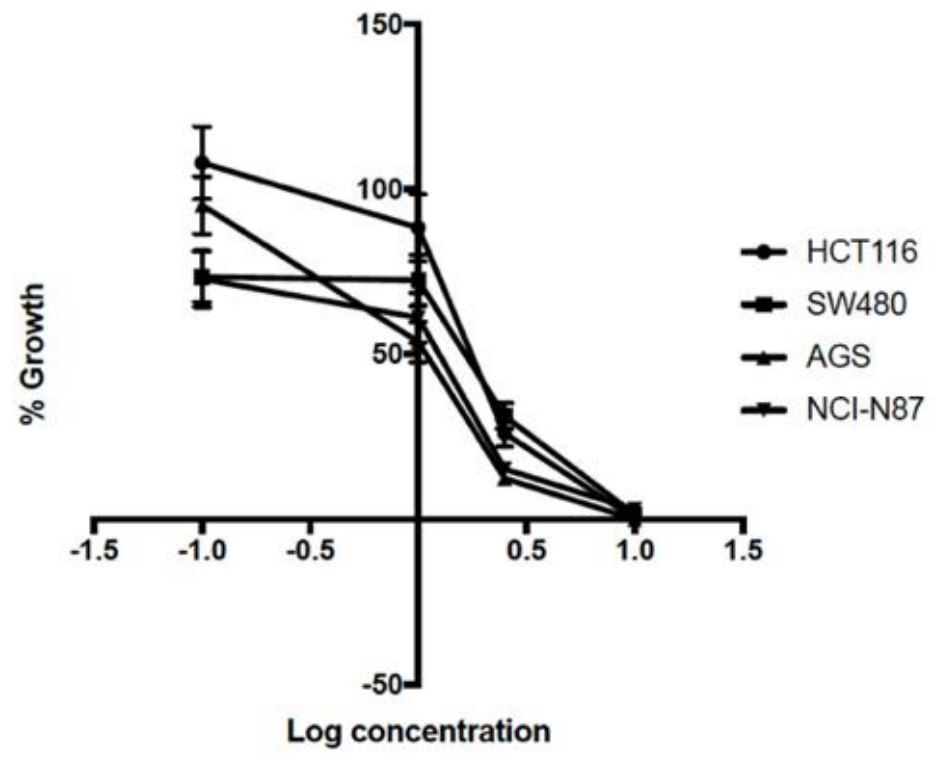

Figure 4. Concentration-dependent effects of ATRA on gastric and colon cancer cell proliferation.

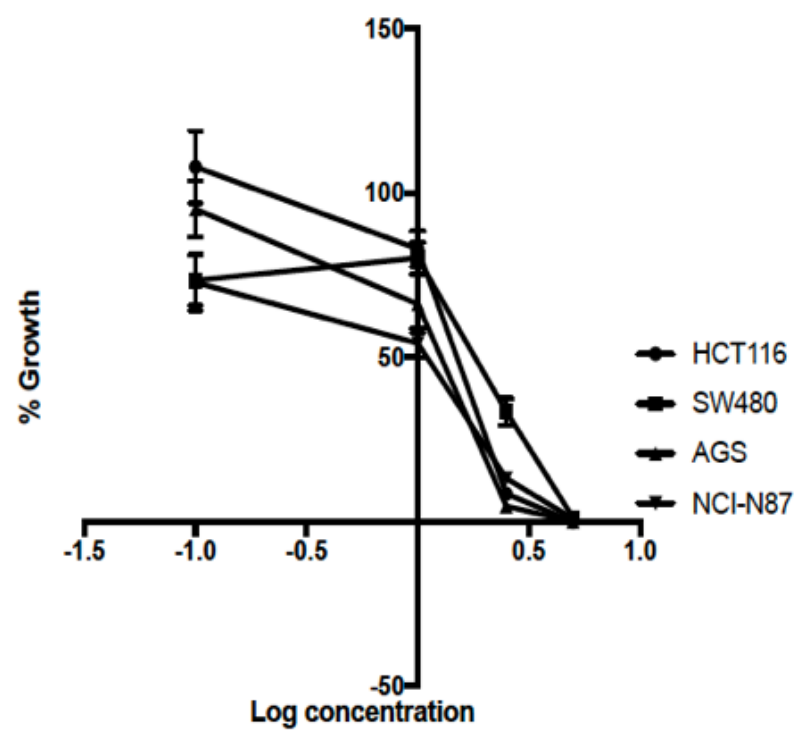

Figure 5. Concentration dependent effects of the combination of vitamins D2, D3, and ATRA on colon and gastric cancer cell proliferation.

Figures 4-5. HCT116 and SW480 colon cancer and AGS and NCI-N87 gastric cells were treated with increasing concentrations of ATRA or the combination D2+D3+ATRA (1:1:1) at 1-10 $\mu \mathrm{g} / \mathrm{mL}$ in 96 well plates and incubated at $37^{\circ} \mathrm{C}$ in $5 \% \mathrm{CO}_{2}$ for 72 hours. Cell proliferation/cytotoxicity was determined using a CellTiter-Glo® 2.0 Reagent. Luminescence signal was determined using a Synergy HT Plate reader (Biotek, Winooski, VT) and Gen5 1.11 software. Each figure shows a concentration dependent reduction in HCT116 and SW480 colon cancer and gastric cancer cell lines AGS and NCI-N87 after treatment. 
Statistical analysis of the differences between the $\mathrm{IC}_{50}$ concentrations for ATRA treatments alone and the ATRA+D2+D3 combination treatment of HCT116 colon cancer, and the AGS and NCI-N87 gastric cancer cell lines showed that the $\mathrm{IC}_{50}$ for the combination was significantly lower $(* * * * \mathrm{p}<0.0001)$ than that of ATRA alone in all three cell lines (Figure 6).

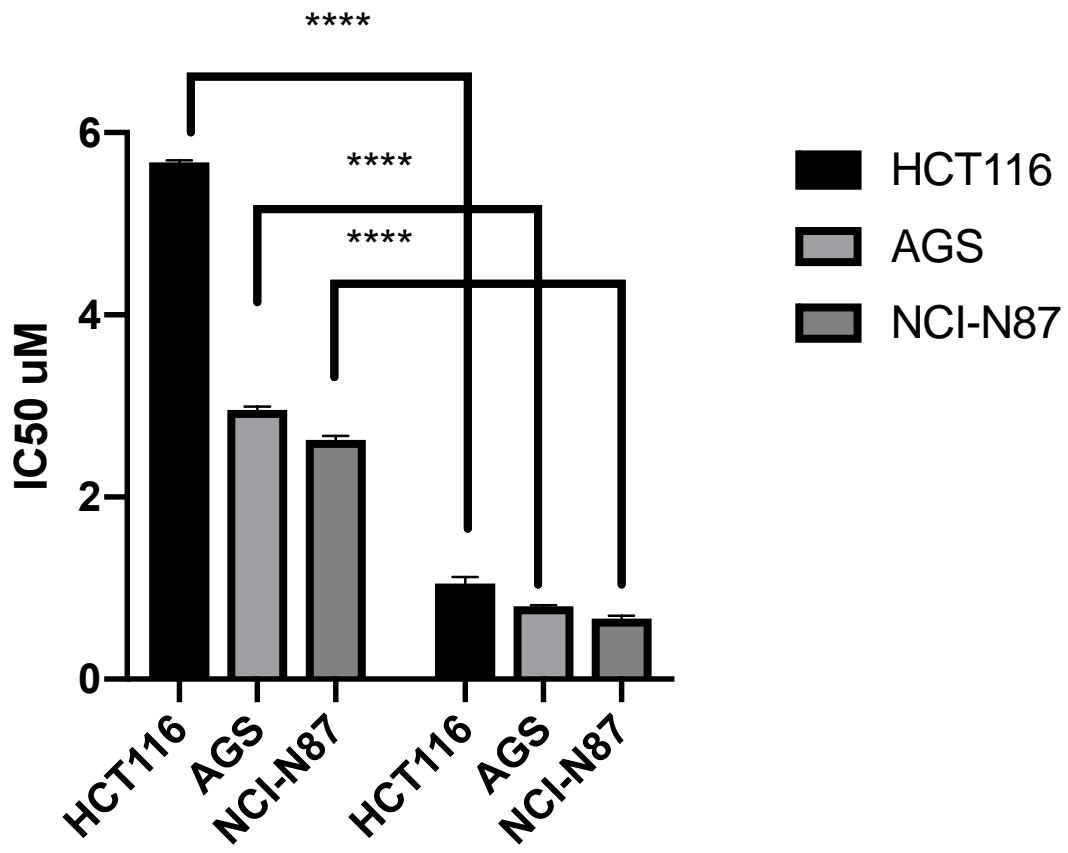

Figure 6. Statistical analysis of the change in $\mathrm{IC}_{50}$ concentrations in HCT-116, AGS and NCI-N87 cells treated with ATRA (left columns) or the combination ATRA+D2+D3 (right columns) shows that the combination was more effective than ATRA alone. The change in the $\mathrm{IC}_{50}$ was statistically significant $(* * * * 0.0001)$. The statistics were performed using one-way ANOVA, followed by Tukey's Multiple Comparison test, with $\mathrm{p}<0.05$ considered statistically significant.

\section{Time study of ATRA+D2+D3 treated cells and cytotoxicity}

In timed studies, the ATRA+D2+D3 combination and the D2+D3 combination reduced cell proliferation, and increased cytotoxicity and caspase activities in SW480 and HCT-116 CC cells and AGS GC cells as compared with D2 or D3 alone and reduced the time to cytotoxicity (Figures 7-9). When compared with negative controls (cells treated with DMSO 0.01\%), a 50\% inhibition of SW480 cell proliferation was observed at 8 hours for D2 or D3 alone, and the combination of D2+D3 (Figure 7). However, SW480 cells treated with the ATRA+D2+D3 combination showed a $50 \%$ reduction of cell proliferation at 4 hours (Figure 7). After treatment with ATRA+D2+D3, significant cytotoxicity ( $\mathrm{p}<0.0001$ ) was observed in SW480 cells between 2-24 hours as compared with D2 or D3 alone, or the D2+D3 combination (Figure 8). A similar pattern was observed in HCT-116 cells (Figures 9A and B) where the combination of ATRA+D2+D3 reduced cell proliferation more rapidly than D2 or D3 alone, and significantly induced cytotoxicity after 8 hours of treatment $(\mathrm{p}<0.0001)$. 


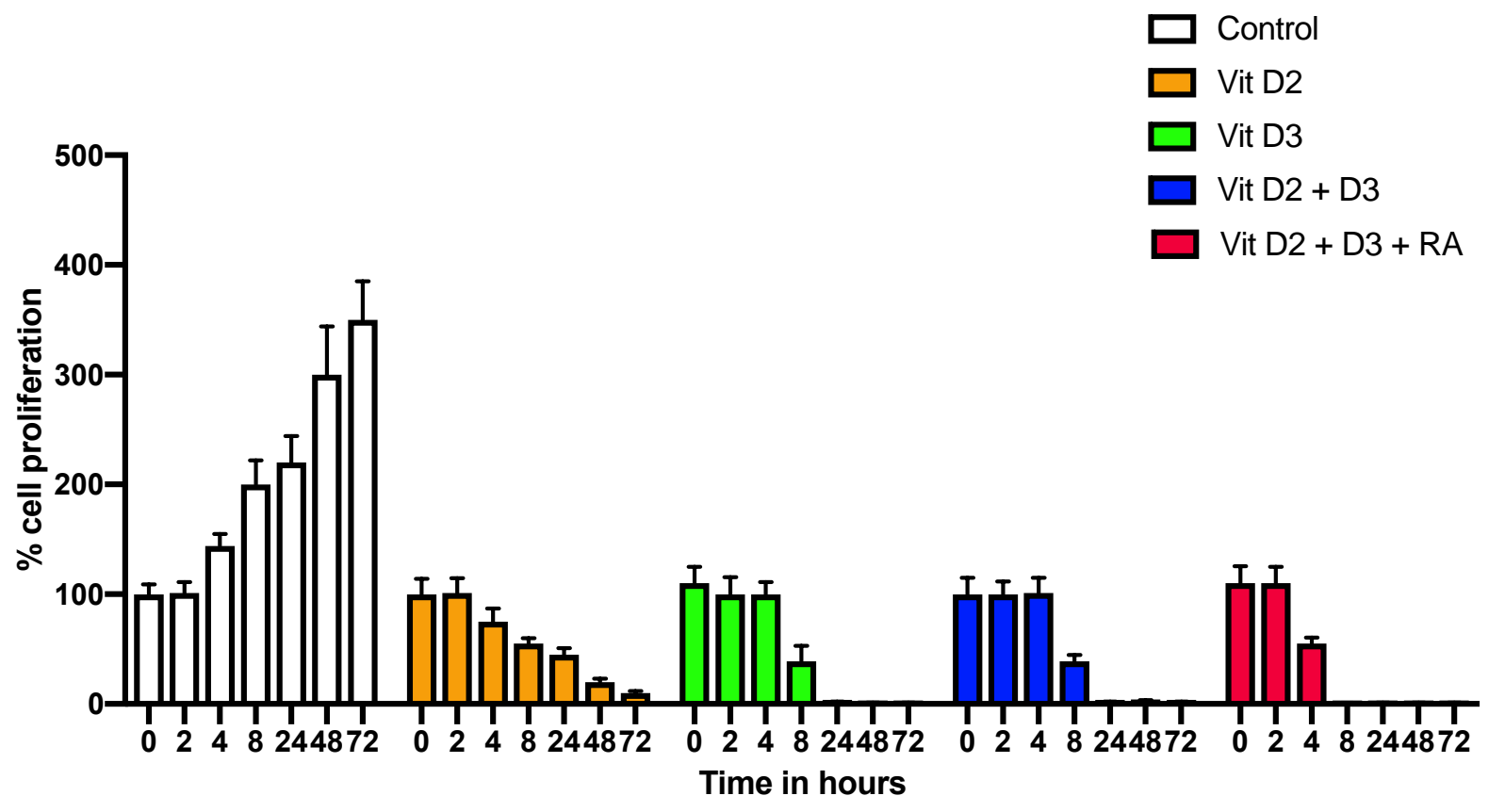

Figure 7. Comparison time study of the proliferation of SW480 colon cancer cells treated with the $\mathrm{IC}_{50}$ concentration of D2 or D3 or the combination of ATRA+D2 + D3 or control (vehicle solvent $0.01 \%$ DMSO) and cell were harvested up to 72 hours to determine kill times.

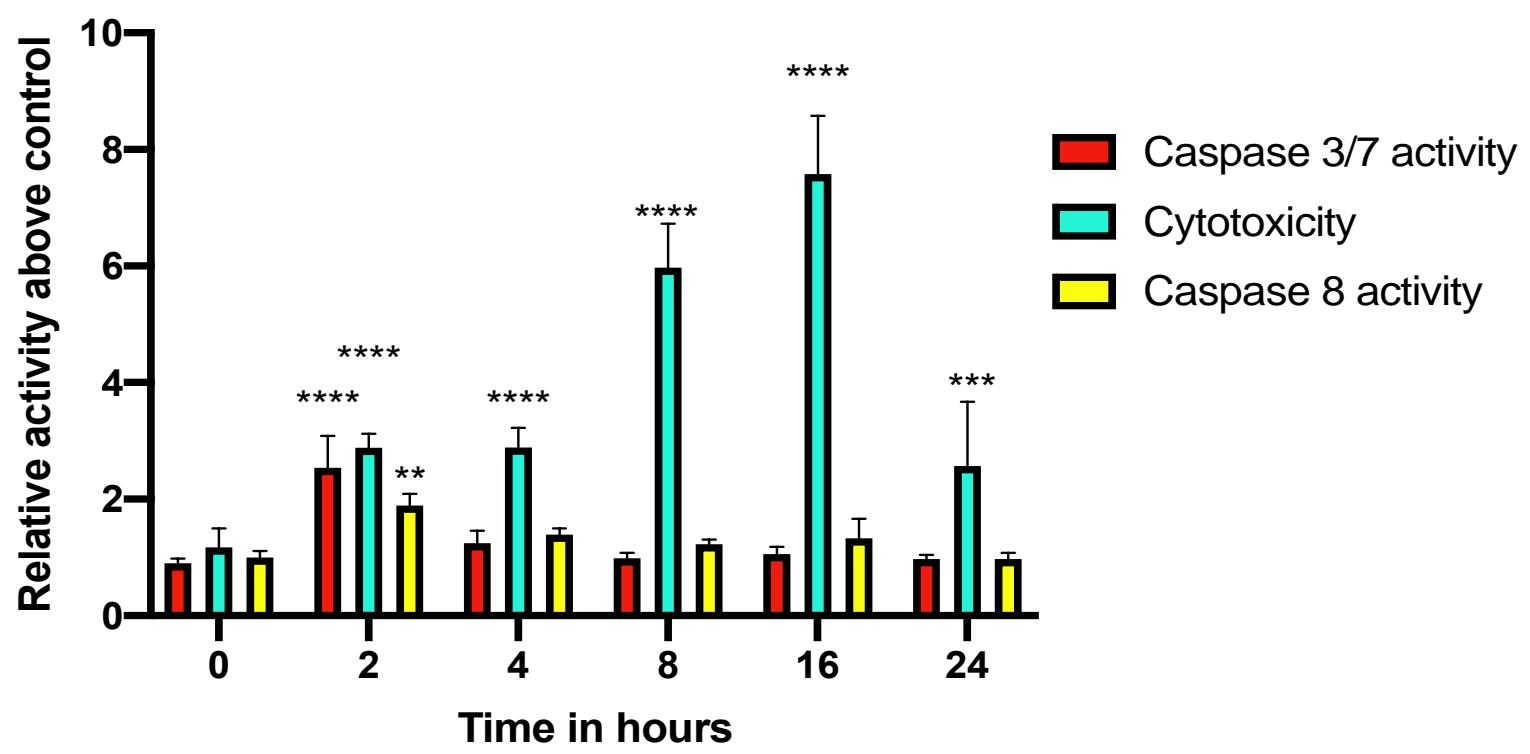

Figure 8. Caspase $3 / 7$ and 8 were activated in SW480 colon cancer cells treated with the $\mathrm{IC}_{50}$ of the combination D2+D3+ATRA. Induction of apoptosis by caspase activation was determined by the ApoTox-Glo ${ }^{\mathrm{TM}}$, Caspase-Glo®3/7 and Caspase-Glo®8 assay kits (Promega). Treated cells were incubated appropriately at different time before addition of assay reagents according to manufacturer's instructions. Luminescence was measured using the Synergy HT Plate reader and Gen5 1.11 software to detect caspase activation. Activity above control values was considered activation of caspase 3/7 and 8. Statistics were performed using oneway ANOVA, followed by Dunnett's Multiple Comparisons test, comparing all other time points against time zero $(0) . * * * * \mathrm{p}<0.0001 ; * * * \mathrm{p}<0.001 ; * * \mathrm{p}<0.01$. 


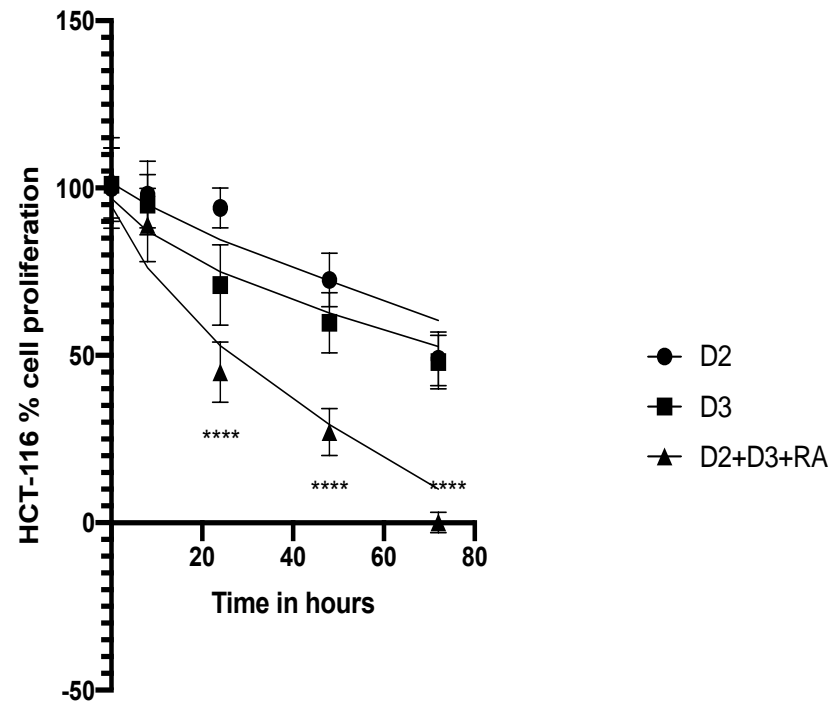

Figure 9A. Time kill study for vitamins D2, D3 or the D2+D3+ATRA combination in HCT-116 colon cancer cells. Cells were treated with the $\mathrm{IC}_{50}$ concentration of $\mathrm{D} 2, \mathrm{D} 3$ or the combination of $\mathrm{D} 2+\mathrm{D} 3+$ ATRA and cell were harvested up to 72 hours determine cytotoxicity. Statistics were performed using one-way ANOVA, followed by Tukey's Multiple Comparisons test, comparing all other time points against time zero (0). ****p $<0.0001$. As compared with D2 or D3, the combination was significantly faster at increasing cell death.

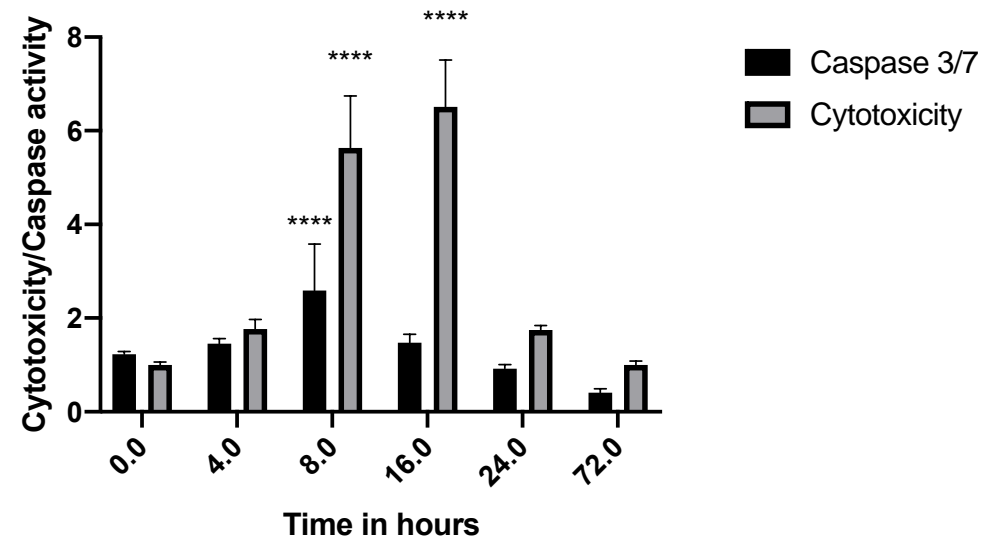

Figure 9B. Effects of combination of Vitamin D2, D3, and ATRA on the cytotoxicity and caspase 3/7 activity in HCT116 colon cancer cells. Caspase 3/7 was activated in HCT-116 colon cancer cells treated with the $\mathrm{IC}_{50}$ of the combination $\mathrm{D} 2+\mathrm{D} 3+\mathrm{ATRA}$. Induction of apoptosis by caspase activation was determined by the ApoTox-Glo ${ }^{\mathrm{TM}}$ and Caspase-Glo®3/7 assay kits (Promega). Treated cells were incubated appropriately at different time before addition of assay reagents according to manufacturer's instructions. Luminescence was measured using the Synergy HT Plate reader and Gen5 1.11 software to detect caspase activation. Activity above control values was considered activation of caspase 3/7. No effect on caspase 8 activity was observed in HCT-116 cells. Activity above control values was considered activation of caspase 3/7 and 8. Statistics were performed using one-way ANOVA, followed by Dunnett's Multiple Comparisons test, comparing all other time points against time zero (0). ****p< 0.0001 ; $* * * \mathrm{p}<0.001 ; * * \mathrm{p}<0.01$

$A T R A+D 2+D 3$ treatments induce apoptosis by increasing caspase activities and the Bax/Bcl-2 gene expression ratio

Measurement of caspase 3/7 and 8 activities over a 72 hour time period showed that treatment with the combination of ATRA+D2+D3 significantly increased caspase $3 / 7$ and 8 activation $(\mathrm{p}<0.0001$ and $\mathrm{p}<0.001$, respectively) in SW480 colon cancer cells at 2 hours (Figure 8), and in HCT-116 
cells at 8 hours $(\mathrm{p}<0.0001$; Figure 9B). These data suggest that the combination treatment induced apoptosis, with the activation of executioner caspases 3 and 7 playing a predominant role in both HCT116 and SW480 cells, as well as activation of the initiator caspase 8 in SW480 cells. These data corresponded with a concomitant increase in cytotoxicity (Figures 8 and 9B). The results suggest the involvement of the intrinsic apoptotic pathway in HCT-116 cells, and possibly both the intrinsic and extrinsic apoptotic pathways in SW480 cells. Similar effects were observed in AGS GC cells with the ATRA+D2+D3 combination significantly ( $p<0.001$ ) inducing caspase 3/7 activities, suggesting the induction of intrinsic apoptosis. These data also correlated with a significant increase in cytotoxicity $(\mathrm{p}<0.0001)$ and reduction in cell viability $(\mathrm{p}<0.01)$ at $4-8$ hours in SW480 cells (Figure $10 \mathrm{~A}$ and B).

Since the induction of caspases is well known to up-regulate the expression of the proapoptotic protein Bax, as well as reduce expression of the anti-apoptotic protein $\mathrm{Bcl}-2$, we investigated the expression of Bax and Bcl-2 mRNA, and the Bax/Bcl-2 ratio in treated cells, using qPCR. The quantitation of gene expression was performed using $\beta$-actin gene as an endogenous control and relative to the calibrator (control cells) using the $\triangle \triangle C T$ method. Treatment of HCT116 with the combination of ATRA+D2+D3 at the $\mathrm{IC}_{50}$ for 4 hours significantly reduced Bcl-2 mRNA expression by $~ 50 \%$ ( $<<0.0001)$ and increased BAX mRNA expression by $35 \%(\mathrm{p}<0.01)$, as well as significantly increased the Bax/Bcl-2 ratio $(\mathrm{p}<0.0001)$ indicating the induction of intrinsic apoptosis in HCT-116 CC cells (Figure 11A). Treatment of SW480 CC cells with the combination of ATRA+D2+D3 at the $\mathrm{IC}_{50}$ for 4 hours significantly increased BAX mRNA expression ( $\mathrm{p}<0.0001)$, as well as significantly increased the $\mathrm{Bax} / \mathrm{Bcl}-2$ ratio by $\sim 3$ fold $(\mathrm{p}<0.0001)$ indicating the induction of intrinsic apoptosis in HCT-116 CC cells (Figure 11B). No effect was observed on Bcl-2 mRNA expression in SW480 cells.

10A

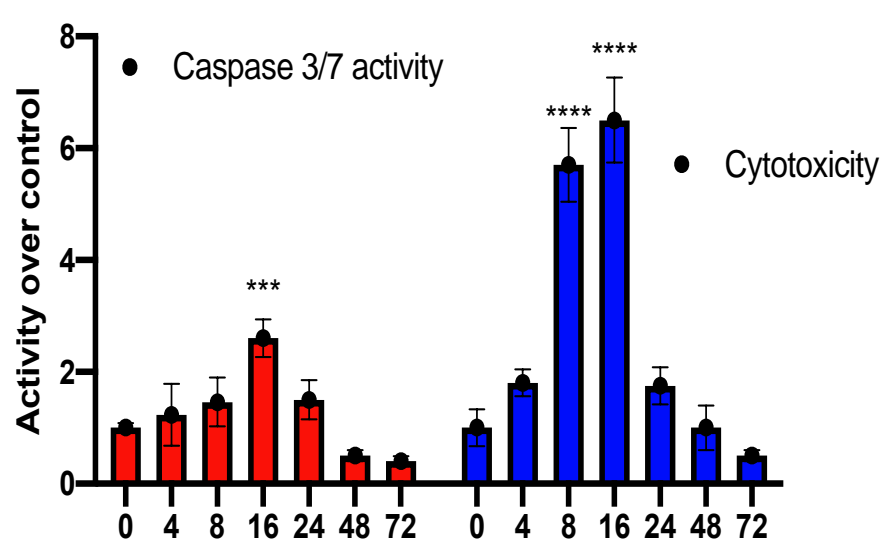

Time in hours
10B

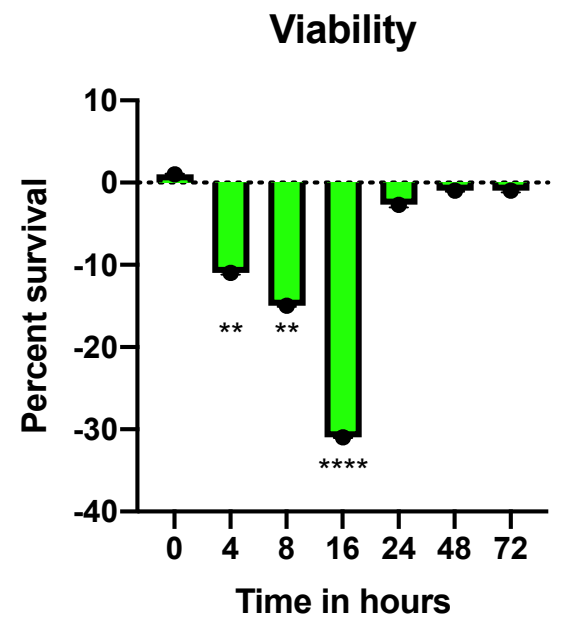

Figure 10A-B. A. Caspase $3 / 7$ was activated in AGS gastric cancer cells treated with the $\mathrm{IC}_{50}$ of the combination ATRA+D2+D3. Induction of apoptosis by caspase activation, cytotoxicity and viability were determined by the ApoTox-Glo ${ }^{\mathrm{TM}}$ and Caspase-Glo®3/7 assay kits (Promega). Treated cells were incubated appropriately at different time before addition of assay reagents according to manufacturer's instructions. Luminescence was measured using the Synergy HT Plate reader and Gen5 1.11 software to detect caspase activation. Activity above control values was considered activation of caspase 3/7. B. Reduction in AGS cell viability after treatment corresponded with the increase in cytotoxicity. Statistics were performed using one-way ANOVA, followed by Dunnett's Multiple Comparisons test, comparing all other time points against time zero $(0) . * * * * p<0.0001$; $* * * \mathrm{p}<0.001 ; * * \mathrm{p}<0.01$. 


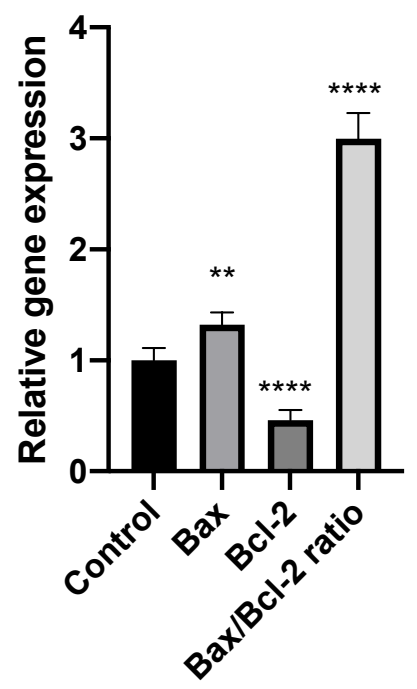

Figure 11A. Expression of Bax and Bcl-2 and the Bax/Bcl-2 ratio in HCT-116 cells treated with a combination of vitamins D2+D3=ATRA as compared with control

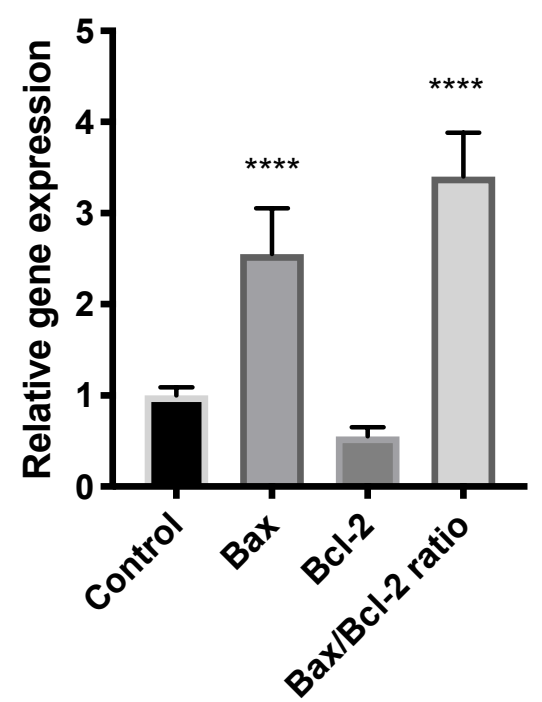

Figure 11B. Expression of $\mathrm{Bax}$ and $\mathrm{Bcl}-2$ and the $\mathrm{Bax} / \mathrm{Bcl}-2$ ratio $\mathrm{SW} 480$ colon cancer cells treated with a combination of vitamins D2+D3+ATRA as compared with control.

Figures 11A-B. Apoptotic gene expression of Bax and Bcl-2 in HCT-116 and SW480 was determined after treatment with the $\mathrm{IC}_{50}$ of the combination of $\mathrm{D} 2+\mathrm{D} 3+\mathrm{ATRA}$ or vehicle control for 4 hours after which total RNA was isolated using the Trizol method. Total RNA was reverse transcribed and amplified using Power SYBR Green RNA- to-CT 1- step kit for gene quantification. The quantitation of gene expression was performed using $\beta$-actin gene as an endogenous control and relative to the calibrator (control cells) using the $\Delta \Delta C T$ calculation. Statistics were performed using one-way ANOVA, followed by Dunnett's Multiple Comparisons test, comparing all other time points against time zero $(0)$. ****p $<0.0001 ; * * * \mathrm{p}<0.001 ; * * \mathrm{p}<0.01$.

In AGS gastric cancer cells, treatment with ATRA+D2+D3 for 4 hours also increased Bax expression and reduced $\mathrm{Bcl}-2$ expression, thereby increasing the $\mathrm{Bax} / \mathrm{Bcl}-2$ ratio to favor apoptosis, also suggesting the involvement of intrinsic apoptosis (data not shown). 


\section{The combination of ATRA+D2+D3 induced autophagy in SW480 colon cancer cells}

In addition to apoptosis, our data further suggested that the combination of ATRA+D2+D3 induced autophagy in SW480 colon cancer cells. Autophagy is a known mechanism by which cells can recycle or remove unnecessary proteins and whole organelles [32-35]. While autophagy is normally thought to be a cytoprotective process to maintain healthy normal cells, increased activation of autophagy under specific certain circumstances has been linked to apoptosis [32-35]. Microplate-based profiling of autophagy in SW480 cells is shown in Figure 12. SW480 cells were stained with a CYTO-ID® Green Detection Reagent 2 after being cultured for 20 hours in DMSO (control), $0.5 \mu \mathrm{M}$ Rapamycin (RPM) [35], $10 \mu \mathrm{M}$ Chloroquine (CLQ), or both $0.5 \mu \mathrm{M}$ RPM and $10 \mu \mathrm{M}$ CLQ or D2 or D3 or D2+D3 or the combination ATRA+D2+D3 at the IC 50 concentration. In this assay, positive control cells treated with RPM (500 nM) or RPM (500 nM) + CHQ (10 $\mu \mathrm{M})$ induced autophagy of (Figure 12, 3.0 and 4.5), while values of $\sim 2.0$ and 2.6 were observed for the combination of D2+D3 ( $p<0.05)$ and the combination of D2+D3+ATRA $(\mathrm{p}<0.0001)$, respectively suggesting the induction of autophagy. No statistical difference was observed in SW480 cells treated with D2 or D3 alone (Figure 12). No induction of autophagy was observed in HCT116 or AGS cells with any of the treatments.

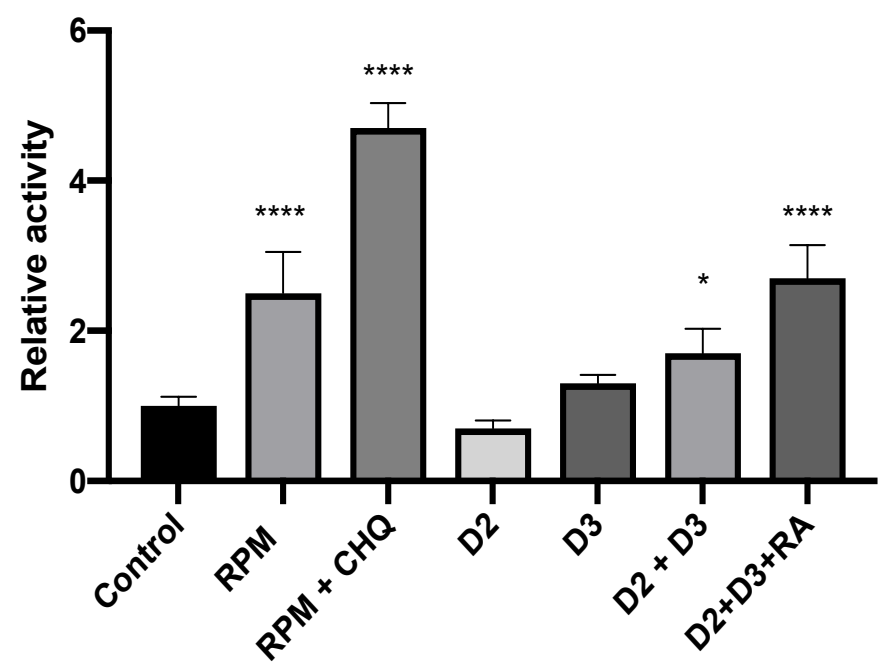

Figure 12. Microplate-based profiling of autophagy in SW480 colon cancer cells. SW480 cells were stained with the CYTO-ID® Green Detection Reagent 2 after being cultured for $18 \mathrm{hr}$ in DMSO 0.01 (negative control), $0.5 \mu \mathrm{M}$ Rapamycin (RPM, positive control), or $10 \mu \mathrm{M}$ Chloroquine (CHQ), and both $0.5 \mu \mathrm{M}$ Rap and $10 \mu \mathrm{M}$ CHQ or D2 or D3 or D2+D3 or ATRA+D2+D3 at the $\mathrm{IC}_{50}$ concentration. Cells were also stained with Hoechst 33342 for cell number normalization. Cells treated with RPM, RPM+CHQ or D2+D3 or the ATRA+D2+D3 combination showed an increase in autophagic activity in SW480 cells, as measured by the CYTOID® Green Detection Reagent 2.Treated cells were analyzed at excitation $\sim 480 \mathrm{~nm}$, emission $\sim 530 \mathrm{~nm}$ for Cyto-ID green and excitation $\sim 340 \mathrm{~nm}$. Statistics were performed using one-way ANOVA followed by Tukey's multiple comparison test using GraphPad/Prism 8.0. *p< 0.05; ****p<0.0001 as compared with controls.

\section{DISCUSSION}

Previously published works have reported the anti-proliferative effects of vitamin D (cholecalciferol, calciferol) in colon cancer (CC) cell lines, including Caco-2 cells [36-39], HT-29 [40-42]; SW480-ADH cells [43], HCT116 and CBS [44]. More recently, the combination of vitamin D3 with metformin or other cancer chemotherapeutic drugs (such as 5-FU) has been 
shown to increase cytotoxicity, and enhance cancer cell apoptosis by upregulating pro-apoptotic proteins (including Bax) and downregulating the anti-apoptotic protein Bcl-2 [45-47]. In addition to vitamin $\mathrm{D}$ and the retinoids (vitamin A derivatives) have been reported to inhibit cancer cell growth, induce differentiation, and cytotoxicity in breast, leukemia, neuroblastoma, prostate and gastric cancers by interacting with retinoid receptors [48-52]. However, very few studies have investigated the anti-proliferative effects of combinations of vitamin A and D in cancer cells. In 1999, Muto et al. reported that the addition of 1,25-dihydroxyvitamin (D3) to a retinoic acidresistant acute promyelocytic leukemia cell line induced differentiation [53]. In 2006, Lu and Zheng reported that a combination of ATRA and D3 exerted synergistic inhibitory effects on the growth of the human hepatoma cell line HepG2 [54]. In a more recent 2013 study, Sha et al. reported that the combination of vitamin A and vitamin D3 significantly increased prostate cancer cells apoptosis, by enhancing Bax expression and reducing Cyclin D1 expression [55]. Vitamin D2 has been much less investigated as an anticancer agent, with the exception of MT19c, a semisynthetic ergocalciferol derivative, that induced cytotoxicity in SKOV-3, BXPC-3 (pancreatic cancer), PC-3 and LNCaP (prostate cancer), SMS-KCNR, SK-N-SH and SH-SY5Y (neuroblastoma) cancer cell lines, where it induced caspase-dependent apoptosis, DNA fragmentation and cell cycle arrest [56]. However, no previous studies have reported the effects of D2 in gastric and cancer cells, or the combinations of D2+D3 or ATRA+D2+D3 in colon and gastric cancer cell lines.

In this study, both vitamin D3 and D2 alone inhibited the proliferation of both gastric and colon cancer cells in a concentration and time-dependent manner. When D2 and D3 were combined, the effects of the combination were highly synergistic in HCT-116 CC cells and had additive effects in SW480 CC cells. In the GC cells lines AGS and NCI-N87, the combination of D2+D3 was also highly synergistic. In addition, treatment of SW480, HCT116, AGS and NCIN87 cells with ATRA alone also inhibited the proliferation of all cell lines in a concentration and time dependent manner. However, when ATRA was combined with D2+D3, the combination was highly synergistic and significantly reduced the $\mathrm{IC}_{50}(\mathrm{p}<0.0001)$ and the time to cell death. In the time kill studies of HCT116 and SW480 CC cells, D3 appeared to be slightly more effective than D2 at 24 hours, but the combination of ATRA+D2+D3 significantly $(p<0.0001)$ inhibited cell proliferation at 24-72 hours, as compared with D2 or D3 alone. Furthermore, treatment of both HCT-116 and SW480 CC cells with the combination of ATRA+D2+D3 significantly increased cytotoxicity in SW480 cells at 2-24 hours, and in HCT-116 cells at 8-16 hours (p < 0.0001). In AGS GC cells, the combination of ATRA+D2+D3 significantly reduced cell viability $(\mathrm{p}<0.01)$ and increased cytotoxicity ( $\mathrm{p}<0.0001)$ at $8 \mathrm{hrs}$.

Previously published studies have shown that vitamins A and D increased apoptosis in cancer cells [53-57]. In mammalian cells there are two distinct, but convergent, apoptotic pathways [5859]. The intrinsic or mitochondrial pathway is regulated by the Bcl-2 family of proteins, and the extrinsic or death receptor pathway that is activated by members of the tumor necrosis factor receptor family [58-59]. In the Bcl-2-regulated pathway, apoptosis is initiated by the transcriptional and/or posttranscriptional upregulation of the pro-apoptotic members of the Bcl-2 protein family (Bax, Bak) [58]. These proteins bind and inhibit the pro-survival Bcl-2 proteins (Bcl-2, Bcl-XL) and activate the death effectors, Bax and Bak leading to increased permeability of the mitochondrial outer membrane and release of cytochrome thereby activating a cascade of 
aspartate specific cysteine proteases (caspases) and inducing apoptosis [58-59]. In the extrinsic pathway, apoptosis is activated by the recruitment and activation of the pro-form of caspase- 8 , often with consequential activation of the effector caspases (caspase-3 and -7) [58-59]. In this work, treatment of HCT-116 and SW480 cells with the combination of ATRA+D2+D3 significantly increased the expression of Bax mRNA $(p<0.01$ for HCT-116; $p<0.0001$ for SW480), while expression of Bcl-2 expression was significantly decreased only in SW480 cells between 4-8 hours. The ratio of Bax/Bcl-2 was also significantly increased in both $\mathrm{CC}$ lines ( $\mathrm{p}<$ $0.0001)$ at these time points indicating induction of apoptosis. These data correlated with significant activation of caspase 3/7 in SW480, HCT-116 and AGS cells ( $p<0.0001$ ). In SW480 cells, treated with the combination of ATRA+D2+D3, there was also a significant increase in caspase 8 activity ( $p<0.01$ ) at 2 hours, suggesting that the extrinsic pathway may also be involved in apoptosis in this cell line. Previous studies have shown that treatment of AML with ATRA alone induced apoptosis through activation of cleaved caspase 3 in AML cancer cells [60]. Our data support these results, and further suggest that the combination of ATRA+D2+D3 induces caspase 3/7 activities in HCT-116 and AGS GC cells. Treatment of SW480 CC cells with the ATRA+D2+D3 increased caspase $3 / 7$ and 8 activities suggesting that both the intrinsic and extrinsic apoptotic pathways may be involved in this cell line. Earlier investigations have also shown that ATRA treatments inhibited cell cycle progression and increased apoptosis in GC cell lines, as well as reduced GC tumor growth in vivo [61, 62]. Our data confirmed the in vitro antiproliferative and apoptotic effects of ATRA in GC cells, supporting these published works, but further suggest that the combination ATRA+D2+D3 was more effective than ATRA alone, and synergistically reduced GC cell proliferation, as well as induced apoptosis. Interestingly, ATRA, and its combination with vitamins D2 and D3, were more effective in reducing AGS cell proliferation than 5-FU (Table 2).

Like apoptosis, autophagy is a highly regulated and conserved process used by eukaryotic cells to induce lysosome-mediated intracellular degradation and recycle the dysfunctional cellular components [63-64]. Activation of autophagy proceeds through the inhibition of the mammalian target of rapamycin (mTOR), and other autophagy-related proteins [63-64]. mTOR is a protein kinase that controls cell growth, proliferation, and survival that is often upregulated in cancer. Rapamycin (RPM) binds to mTOR at a domain separate from the catalytic site and induces autophagy. The process of autophagy is considered to include tumor suppression based on indirect evidence from oncogene and tumor suppressor gene alteration studies [63-64]. In this work, treatment of SW480 cells with RPM ( $<<0.0001)$ or RPM+CLQ $(\mathrm{p}<0.0001)$ or D2+D3 ( $<<0.05)$, or ATRA+D2+D3 $(\mathrm{p}<0.0001)$ significantly increased autophagic activity, suggesting that the combination may also inhibit mTOR and downstream signaling. These effects were not observed in any of the other three cell lines. Thus, in addition to apoptosis, the combination of ATRA+D2+D3 may also act in SW480 cells through the initiation of autophagy.

\section{CONCLUSIONS}

A growing body of evidence supports the hypothesis that combinations of vitamin A and D may be more effective than either vitamin alone in epithelial cell cancers, which may have significant clinical impact. It has been suggested that the anticancer effects of vitamin A and D may be mediated through their respective receptors $[9,10]$. Vitamin A (retinoids) are ligands for the 
retinoic acid receptor (RXR), and both vitamin D2 and D3 are ligands for the (vitamin D receptor, VDR). After ligand binding, these two receptors then form heterodimers, a VDR-RXR complex, that can enhance or inhibit transcription of target genes [53]. In this study, we have demonstrated that ATRA, D2, and D3 inhibit the growth of four gastric and colon cancer cells, and when used in combination, have synergistic effects and significantly reduce the $\mathrm{IC}_{50}$ concentrations. Thus, it is possible that the synergistic effects of vitamin A and D combinations may be mediated through enhanced formation of the VDR-RXR complex and gene transcription. The mechanisms by which the combination works appear to be pleiotropic in that they involve the regulation of signaling pathways involved in cell survival/apoptosis (Bcl-2, Bax, caspase 3/7), and autophagy (mTOR). Further investigations of the combinations are currently underway in mouse xenograph models, and to determine the molecular mechanisms of action.

Competing interests: There are no conflicts of interest to declare.

Authors' contributions: GBM, TOL, SP, NR designed and conducted the research, and performed statistical analyses. GBM, SMW and NR wrote and edited the manuscript.

\section{Acknowledgements}

This work was supported in part by the generous educational sponsorship from the First Analysis Institute of Integrative Studies (GBM); a research grant from the Regenstein Foundation (GBM); a Postdoctoral fellowship award from the Schlumberger Foundation (TOL/GBM); and a Raman Post-Doctoral Fellowship by the University Grants Commission, Govt. of India to NAR. The contents are solely the responsibility of the authors and do not necessarily represent the official views of the funding agencies. We would like to express our sincere appreciation to F. Oliver Nicklin at the First Analysis Institute of Integrative Studies for the theoretical discussions, as well as his assistance with hypothesis generation and the direction of the work.

\section{REFERENCES}

1. Garland CF, Garland FC: Do sunlight and vitamin D reduce the likelihood of colon cancer? Int J Epidemiol 1980, 9:227-231.

2. Garland CF, Comstock GW, Garland FC, Helsing KJ, Shaw EK, Gorham ED: Serum 25hydroxyvitamin D and colon cancer: eight-year prospective study. Lancet 1989, 2: 11761178.

3. Hanchette CL, Schwartz GG: Geographic patterns of prostate cancer mortality: evidence for a protective effect of ultraviolet radiation. Cancer 1992, 70:2861-2869

4. Giovannucci E: Vitamin D status and cancer incidence and mortality. Adv Exp Med Biol 2008, 624:31-42.

5. Garland CF, Gorham ED, Mohr SB, Grant WB, Giovannucci EL: Vitamin D and prevention of breast cancer: pooled analysis. J Steroid Biochem Mol Biol 2007, 103:708-711.

6. Garland CF, Garland FC, Gorham ED, Lipkin M, Newmark H: The role of vitamin D in cancer prevention. Am. J. Public Health 2006, 96:252-261.

7. Grant W: A review of the evidence supporting the vitamin D-cancer hypothesis in 2017. Anticancer Res 2018, 38:1121-1136. 
8. Bikle D: Vitamin D Metabolism, Mechanism of Action, and Clinical Applications. Chem Biol 2014, 21(3): 319-329.

9. Mahendra A, Karishma, Choudhury BK, Sharma T, Bansal N, Bansal R, Gupta S: Vitamin D and gastrointestinal cancer. J Lab Physicians 2018, 10(1):1-5.

10. Dou R, Ng K, Giovannucci E, Manson JE, Qian R, Ogino S: Vitamin D and Colorectal Cancer: Molecular, Epidemiological, and Clinical evidence. Br J Nutr 2016, 115: $1643-$ 1660.

11. Ng K, Meyerhardt JA, Wu K, Feskanich D, Hollis BW: Circulating 25-hydroxyvitamin D levels and survival in patients with colorectal cancer. J Clin Oncol 2008, 26:2984-2991.

12. Siddikuzzaman, GC, Berlin GVM: All-trans retinoic acid and cancer. Immunopharmacol Immunotoxicol 2011, 33:241-249.

13. Niles RM: Signaling pathways in retinoid chemoprevention and treatment of cancer. Mutat Res 2004, 555: 81-96.

14. Bouriez D, Giraud J, Gronnier C, Varon C: Efficiency of all-trans retinoic acid on gastric cancer: A narrative literature review. Int J Mol Sci 2018, 19:3388-3401.

15. Wei S, Kozono S, Kats L, Nechama M, Li W, Guarnerio J, Luo M, et al.: Active Pin1 is a key target of all-trans retinoic acid in acute promyelocytic leukemia and breast cancer. Nat Med 2015, 21:457-466.

16. Mondul AM, Sampson JN, Moore SC, Weinstein SJ, Evans AM, Karoly ED, Virtamo J, et al.: Metabolomic profile of response to supplementation with $\beta$-carotene in the alphatocopherol, beta-carotene cancer prevention study. Am J Clin Nutr 2013, 98:488-493.

17. Block KI, Gyllenhaal C, Lowe L, Amedei A, Amin AR, Amin A, Aquilano K: Designing a broad-spectrum integrative approach for cancer prevention and treatment. Semin Cancer Biol 2011,35:S276-304.

18. Sha J, Pan J, Ping P, Xuan H, Li D, Bo J, Liu D, Huang Y: Synergistic effect and mechanism of vitamin A and vitamin D on inducing apoptosis of prostate cancer cells. Mol Biol Rep 2013, 40:2763-2768.

19. Chen X, Sun K, Jiao S, Cai N, Zhao X, Zou H, Xie Y, et al.: High levels of SIRT1 expression enhance tumorigenesis and associate with a poor prognosis of colorectal carcinoma patients. Sci Rep 2014, 4:7481-7485.

20. Ouaissi M, Silvy F, Loncle C, Ferraz da Silva D, Martins Abreu C, Martinez E, et al: Further characterization of HDAC and SIRT gene expression patterns in pancreatic cancer and their relation to disease outcome. PLoS ONE 2014, 9(10): e108520.

21. Liu Y, Bodmer W: Analysis of P53 mutations and their expression in 56 colorectal cancer cell lines PNAS 2006, 103;976-981.

22. Solomon H, Dinowitz N, Pateras I, Cooks T, Shetzer Y, Molchadsky A, Charni M, et al.: Mutant p53 gain of function underlies high expression levels of colorectal cancer stem cells markers. Oncogene 2018, 37:1669-1684.

23. Scarpulla RC: Metabolic control of mitochondrial biogenesis through the PGC-1 family regulatory network. Biochim Biophys Acta 2011, 1813:1269-1278.

24. Giampazolias E, Tait SW: Mitochondria and the hallmarks of cancer. FEBS J 2016, 283:803814. 
25. Adhihetty PJ, Uguccioni G, Leick L, Hidalgo J, Pilegaard H, Hood DA: The role of PGC1alpha on mitochondrial function and apoptotic susceptibility in muscle. Am J Physiol Cell Physiol. 2009, 297:C217-25.

26. Botelho MG: Fractional inhibitory concentration index of combinations of antibacterial agents against cariogenic organisms. J Dent 2000, 28(8):565-70.

27. Jenkins SG, Schuetz AN: Current concepts in laboratory testing to guide antimicrobial therapy. Mayo Clin Proc 2012, 87:290-308.

28. Pandey A, Vishnoi K, Mahata S, Tripathi SC, Misra SP, Misra V, Mehrotra R, et al.: Berberine and curcumin target survivin and STAT3 in gastric cancer cells and synergize actions of standard chemotherapeutic 5-Fluorouracil. Nutr Cancer 2015, 67:1293-1304.

29. Gao K, Liang Q, Zhao ZH, Li YF, Wang SF: Synergistic anticancer properties of docosahexaenoic acid and 5-fluorouracil through interference with energy metabolism and cell cycle arrest in human gastric cancer cell line AGS cells. World J Gastroenterol 2016, 22:2971-2980.

30. Wang Y, Liu X, Liu J, Zhang T: Knockdown of REG I $\alpha$ Enhances the Sensitivity to 5Fluorouracil of Colorectal Cancer Cells via Cyclin D1/CDK4 Pathway and BAX/BCL-2 Pathways. Cancer Biother Radiopharm 2019, Apr 11. doi: 10.1089/cbr.2018.2746.

31. La X, Zhang L, Li Z, Li H, Yang Y: (-)-Epigallocatechin gallate (EGCG) enhances the sensitivity of colorectal cancer cells to 5-FU by inhibiting GRP78/NF- $\kappa \mathrm{B} / \mathrm{miR}-155-$ 5p/MDR1 pathway. J Agric Food Chem 2019, 67(9):2510-2518.

32. Choi AM, Ryter SW, Levine B: Autophagy in human health and disease. N Engl J Med 2013, 368:651-662.

33. Santana-Codina N, Mancias J, Kinnelman A: The role of autophagy in cancer. Ann Rev Cancer Biol 2017, 1:19-39.

34. White E: The role of autophagy in cancer. J Clin Invest 2015, 125:42-46.

35. Ballou LM, Lin RZ: Rapamycin and mTOR kinase inhibitors. J Chem Biol 2008, 1(1-4):2736.

36. Scaglione-Sewell BA, Bissonnette M, Skarosi S: A vitamin D3 analog induces a G1-phase arrest in CaCo-2 cells by inhibiting cdk2 and cdk6: roles of cyclin E, p21Waf1, and p27Kip1. Endocrinology 2000, 141:3931-3939.

37. Chen A, Davis BH, Bissonnette M: 1,25-Dihydroxyvitamin $\mathrm{D}(3)$ stimulates activator protein-1-dependent Caco-2 cell differentiation. J Biol Chem 1999, 274:35505-35513.

38. Gaschott T, Steinmeyer A, Steinhilber D, et al: ZK 156718, a low calcemic, antiproliferative, and pro-differentiating vitamin D analog. Biochem Biophys Res Commun 2002, 290:504509.

39. Chen AP, Davis BH, Sitrin MD: Transforming growth factor-beta 1 signaling contributes to Caco-2 cell growth inhibition induced by $1,25(\mathrm{OH})(2) \mathrm{D}-3$. American J Physiol Gastroint Liver Physiol 2002, 283:G864-G874.

40. Oh YS, Kim EJ, Schaffer BS, et al: Synthetic low-calcaemic vitamin D(3) analogues inhibit secretion of insulin-like growth factor II and stimulate production of insulin-like growth factor-binding protein-6 in conjunction with growth suppression of HT-29 colon cancer cells. Mol Cell Endocrinol 2001, 183:141-149. 
41. Tong WM, Hofer H, Ellinger A, et al: Mechanism of antimitogenic action of vitamin D in human colon carcinoma cells: Relevance for suppression of epidermal growth factorstimulated cell growth. Oncology Res 1999, 11:77-84.

42. Diaz GD, Paraskeva C, Thomas MG, et al: Apoptosis is induced by the active metabolite of vitamin D3 and its analogue EB1089 in colorectal adenoma and carcinoma cells: possible implications for prevention and therapy. Cancer Res 2000; 60:2304-2312.

43. Aguilera O, Pena C, Garcia JM, et al: The Wnt antagonist DICKKOPF-1 gene is induced by 1alpha,25-dihydroxyvitamin D3 associated to the differentiation of human colon cancer cells. Carcinogenesis 2007, 28:1877-1884.

44. Liu G, Hu X, Chakrabarty S: Vitamin D mediates its action in human colon carcinoma cells in a calcium-sensing receptor-dependent manner: downregulates malignant cell behavior and the expression of thymidylate synthase and survivin and promotes cellular sensitivity to 5-FU. Int J Cancer 2010, 126:631-639.

45. Refaat B, El-Shemi AG, Kensara OA, Mohamed AM, Idris S, Ahmad J, Khojah A:

Vitamin D3 enhances the tumoricidal effects of 5-Fluorouracil through multi-pathway mechanisms in azoxymethane rat model of colon cancer. J Exp Clin Cancer Res 2015, 34:7175.

46. Guo LS, Li HX, Li C, Zhang S, Chen J, Wang QL, Gao J, et al.: Synergistic antitumor activity of vitamin D3 combined with metformin in human breast carcinoma MDA-MB-231 cells involves m-TOR related signaling pathways. Pharmazie 2015, 70:117-122.

47. Dou RX, Ng K, Giovannucci EL, Manson J, Qian Z, Ogino S: Vitamin D and colorectal cancer: Molecular, epidemiology and clinical evidence. Br J Nutr 2016, 115:1643-1660.

48. Stambolsky P, Tabach Y, Fontemaggi G: Modulation of the Vitamin D3 response by cancerassociated mutant p53. Cancer Cell. 2010, 17:273-285.

49. Brard L, Lange TS, Robison K, Kim KK, Ara T, McCallum MM, Arnold LA, et al.: Evaluation of the first Ergocalciferol-derived, non-hypercalcemic anti-cancer agent MT19c in ovarian cancer SKOV-3 cell lines. Gynecol Oncol. 2011,123(2):370-378.

50. Uray IP, Dmitrovsky E, Brown PH: Retinoids and rexinoids in cancer prevention: from laboratory to clinic. Semin Oncol. 2016, 43(1):49-64.

51. Tang XH, Gudas LJ: Retinoids, retinoic acid receptors, and cancer. Annu Rev Pathol 2011, 6:345-364.

52. Abdel-Samad R, Aouad P, Darwiche N: Natural and synthetic retinoids in preclinical colorectal cancer models. Anticancer Drugs 2019, 30(7):e0802.

53. Muto A, Kizaki M, Yamato K, Kawai Y, Kamata-Matsushita M, Ueno H, Ohguchi M, et al.: 1,25-Dihydroxyvitamin D3 induces differentiation of a retinoic acid-resistant acute promyelocytic leukemia cell line (UF-1) associated with expression of p21(WAF1/CIP1) and p27(KIP1). Blood 1999, 93(7):2225-2233.

54. Lu HQ, Zheng J: [Synergistic inhibitory effect of all-trans retinoic acid and 1,25-dihydroxy vitamin D3 on growth of human hepatoma cell line HepG2]. Ai Zheng. 2006, 25(12):14701476. 
55. Sha JJ, Pan JH, Ping P, Xuan H, Li D, Bo JJ, Liu DM, et al.: Synergistic effect and mechanism of vitamin A and vitamin D on inducing apoptosis of prostate cancer cells. Mol Biol Rep 2013, 40:2763-2768.

56. Brard L, Lange Y, Robison K, Singh R: Evaluation of the first Ergocalciferol-derived, non hypercalcemic anti-cancer agent MT19c in ovarian cancer SKOV-3 cell lines. Gyn Oncol 2011, 123:370-378.

57. Hu XT, Zuckerman KS: Role of cell cycle regulatory molecules in retinoic acid- and vitamin D3-induced differentiation of acute myeloid leukemia cells. Cell Prolif 2014, 47(3):200-210.

58. Elmore S: Apoptosis: a review of programmed cell death. Toxicol Pathol 2007, 35(4):495516.

59. Shamas-Din A, Kale J, Leber B, Andrews DW: Mechanisms of action of Bcl-2 family proteins. Cold Spring Harb Perspect Biol 2013, 5(4):a008714.

60. Gianni M, Ponzanelli I, Mologni L: Retinoid-dependent growth inhibition, differentiation and apoptosis in acute promyelocytic leukemia cells. Expression and activation of caspases. Cell Death Differ 2000, 7:447-460.

61. Nguyen PH, Giraud J, Staedel C, Chambonnier L, Dubus P, Chevret E, Bœuf H, et al.: Alltrans retinoic acid targets gastric cancer stem cells and inhibits patient-derived gastric carcinoma tumor growth. Oncogene 2016, 35(43):5619-5628.

62. Bouriez D, Giaurd J, Gronnier C, Varon: Efficiency of all-trans-retinoic acid on gastric cancer: A narrative literature review. Int J Mol Sci 2018, 19:3388-3395.

63. Jung CH, Ro SH, Cao J, Otto NM, Kim DH: mTOR regulation of autophagy. FEBS Lett 2010, 584(7):1287-1295.

64. Kimmelman AC: The dynamic nature of autophagy in cancer. Genes Dev 2011, 25:19992010. 